\title{
Stress management techniques for students
}

\author{
Kassymova K. Gulzhaina, PhD \\ Abai Kazakh National Pedagogical University, \\ Almaty, Kazakhstan \\ zhaina.kassym@gmailcom
}

\author{
Kosherbayeva N. Aigerim, Prof. Dr. \\ Abai Kazakh National Pedagogical University, \\ Head of the Department of Pedagogy and Psychology, \\ Almaty, Kazakhstan
}

Sangilbayev S. Ospan, Prof. Dr.

Abai Kazakh National Pedagogical University, Almaty, Kazakhstan

\author{
Schachl J. Hans \\ University of Education Linz \\ Prof. Dr., Rector em., Austria
}

\author{
Nigel B. C. Cox R., Prof. Lecturer \\ Furzedown College of Education, University of London, \\ London, United Kingdom
}

\begin{abstract}
This paper deals with stress and its biology, which is a major problem for students throughout the modern world. It outlines and suggests stress management techniques, which are easy to practice for students and teachers even during lessons, e.g. japanese finger stress relief techniques and yoga pranayama. Stress is a significant problem of our times and affects both the physical and mental health of people. The main objectives are to ascertain the extent to which stress affects students' academic success and health and to suggest some techniques and pratices to cope with stress for students. Stress coping methods are the physiological, cognitive, behavioral and psychological methods to deal with stress. The main method used has been to gather and analyse the relavant data.

For this purpose questionnaires about stress were randomly distributed to different student groups mostly at three Kazakhstani universities. The results obtained show that students need to be given effective techniques to cope with stress while they are studying. After a thorough literature review in major databases stress management techniques were identified and are presented and briefly discussed here. Stress can be managed through the introduction of a stress management course and engaging in extracurricular physical and mental activities. These techniques are easy to learn and practice, with excelent results in individuals with sound health or even those with health issues. They are beneficial and very helpful for both students and teachers.
\end{abstract}

Keywords: stress, mental health problems and promotion, intervention, treatment, academic performance and stress management techniques, methods and well-being.

\section{INTRODUCTION}

Stress is a reality of everyday life. The term "stress" used first in physics in order to analyze the problem of how manmade structures must be designed to carry heavy loads and resist deformation. With the transition from physics to the behavioral sciences, the usage of the term "stress" changed [1]. According to Wheeler C. M. [2] stress is a word of physics, which refers to the amount of force used on an object and it relates in real life to how certain issues that carry force are applied to humans. Examples like financial difficulties, health issues, personal conflicts and work issues all carry force or pressure on a person's body, mind and spirit. Some of the pressures originate from the environment but most often it emanates from within a person's head in the form of worry, anxiousness, regret, discouragement and low confidence and self-esteem. This article uses the term "stress" in the context of mental health. For roughly the last 50 years the term stress has increasingly been used in the behavioral and health sciences. The accompanying social "theory" explains observations about stress as an aspect of student life. Our findings about stress confirmed, that Kazakhstani students at universities always experience a significant amount of stress during their academic life and they need ways to help to cope with it. Undoubtedly, stress has become the number one reported impediment to academic performance. A Publication of New York University [3] stated that 55\% of students claimed their biggest stressor to be academic in nature. 6 in 10 college students report having felt so stressed they could not do their studies on one or more occasion. Stress is the process by which a person reacts when faced with external or internal problems and challenges. "The organism processes numerous systems to coordinate such adaptive responses both at systematic and cellular levels," that means, stress has direct effects on the brain and the whole anatomy of the body: failure to adapt to a stressful condition can result in brain malfunctions, physiological problems and also areas of psychological challenges in the form of depression, anxiety, pain and burnout [3]. Additionally, many of the emotional and physical symptoms that occur commonly in the student population, such as headaches, fatigue, depression, anxiety, and the inability to cope, can be attributed to or exacerbated by stress [4]. Surveys conducted by Kansas State University reveal a $58 \%$ increase in stress-related mental health issues reported to campus counsellors between 1988 and 2001 [5]. These increased stress loads come with some dire consequences. Suicide rates amongst college-aged students are three times higher than they were in 1950, as described by 
American College Health Association statistics published in Psychology Today (Retrieved on March 10, 2016).

Types of Stressors [3]: When individuals search for help, they are regularly managing conditions, circumstances, and stressors in their life that leave them feeling emotionally and physically disturbed. Countless people feel that they have very little resources or assistance to deal with the high levels of stress they are experiencing. Circumstances that trigger stress are known as "stressors". According to [3] stress is not only because of negative things; positive things also cause stress. In our life we only know stress to be bad but that is not the case. There are two types of stress: eustress and distress. There are some positive situations that cause a person to be stressed, like promotion at work, starting a new job, getting married, having a child, etc. Positive stressors are usually not noticed because of the following characteristics:

- It is a short term event;

- It feels very exciting;

- It improves one's attitude and performance;

- It motivates people.

On the other hand, negative stressors are easily noticed. Examples of negative stressors are: death of a loved one, unemployment, divorce, illness, etc. There are also some characteristics of negative stressors, which make it easier for them to be noticed:

- It causes anxiety and makes one disturbed;

- Even though it may be short, it can have long term implications;

- It decreases ones' productivity and lowers morale.

In the book of Brain by Luke Seaward in G. Essel and P. Owusu [3], he also also mentions some other types of stress which are different in their own ways. For example, there is the neustress and "this is any kind of information or sensory stimulus that is perceived as unimportant".

In this paper we discuss how student stress impacts academic performance and can cause mental health problems and their consequences in academic life. We provide some methods on how to cope with stress and to avoid mental health issues during the study period.

\section{MATERIALS AND METHODS}

\section{The biology of stress}

Although the stress response is very complex, we can focus on two major stress systems.

First: the rapid autonomous nervous system is activated within seconds to release catecholamines from the adrenal medulla and the locus coeruleus in the brain stem. Catecholamines (Adrenalin and Noradrenalin) are implicated in the 'fight-or-flight' response (activation of circulation and breathing, but they also have profound effects on attention, working memory and long-term memory. If after this first action there is no danger, the stress response will be finished! If not, the second action starts: "Somewhat slower, the hypothalamus-pituitary-adrenal axis is activated, releasing corticotropin-releasing hormone $(\mathrm{CRH})$ from the hypothalamus, which stimulates the anterior pituitary to secrete the adrenocorticotropic hormone (ACTH). ACTH in turn causes the adrenal cortex to produce cortisol and release it into the blood stream. Cortisol reaches peak level concentrations $\sim 20-30 \mathrm{~min}$. after stress onset and readily enters the brain to affect cognition and behaviour. Cortisol binds to two different receptors: the glucocorticoid receptor (GR) is expressed ubiquitously throughout the brain, whereas the mineralcorticoid receptor (MR) is mainly expressed in the brain regions related to memory and emotion (Hippocampus, Amygdala, Prefrontal Cortex). On binding to these receptors, cortisol operates via two different modes of action: a nongenomic, often MR-mediated mode develops rapidly and enhances neural excitability in the Amygdala and Hippocampus, presumably supporting memory formation. This rapid mode is followed by a slower, often GR-dependent mode that is assumed to develop about $60.90 \mathrm{~min}$ after stressor onset and to involve longer-lasting changes to DNA translation and transcription" [43].

Cortisol feedback to the pituitary, hypothalamus and other brain areas (e.g. the hippocampus) prevents the system from overshooting. Cortisol is released not only with stress, but in shifts during "normal life", with a peak after awakening [44].

The bodily consequences of stress are well-known: diseases of heart and circulation, of stomach and gut, problems with sexuality, weakening of immune-system, psychiatric disorders and so on!

\section{What time is it?}

Have you ever wondered why you have lots of energy when you wake up (after you have cleared the sleep cobwebs of course) and why you sometimes feel a bit slow in the afternoon? Well, here again, cortisol plays a role.

Cortisol is not only released in times of stress but is also important to many normal or basal bodily functions. To accomplish this we need a steady stream of cortisol in our blood. In fact, cortisol is secreted at a very predictable and pretty much universal rhythm in all of us. This is called a circadian rhythm.

The circadian rhythm of cortisol is as followed: there is the cortisol peak early in the morning, and then cortisol levels decline slowly over the course of the day, and eventually rise again in the early night time hours slowly preparing for the morning peak again.

To summarize, there are two kinds of cortisol hormone levels:

- $\quad$ Resting (basal) cortisol levels. These are the normal everyday levels essential for normal functioning.

- Reactive cortisol levels. These are increases in cortisol in response to stressors [6].

"Prolonged or chronic activation of the HPA axis has been consistently associated with neuronal loss, decreased neurogenesis and altered neural connectivity and ... stress exposure has also been strongly linked to alterations in epigenetic markers that may ultimately lead to changes in gene expression. ...And these epigenetic mechanism could play a role in the pathogenesis of neurodegenerative disorders including Alzheimer Desease“" [7]!

Once again: chronic stress has negative impacts on nerve cells: dendrites shrink, the spine (docking station for other 
nerve cells) density in the hippocampus and prefrontal cortex is reduced. These processes are reversible to some extent, especially in young animals and humans; physical exercise, for example, has a positive influence [8]!

Stress shortens the so-called telomeres and accelerates aging! A telomere is a region of repetitive nucleotide sequences at each end of a chromosome, which protects the end of the chromosome from deterioration or from fusion with neighboring chromosomes. Its name is derived from the Greek

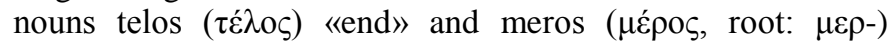
«part» [9].

Important arguments for making teaching and learning less stressful

The stress processes in the brain are very complex and interlinked by different feedback mechanisms. Especially in connection with the awareness of raising and "assessment" of stress situations, it is important that "higher" regions are also affected: Thalamus, neocortex (especially the prefrontal cortex), limbic system, hippocampus, amygdala [10]!

\section{Origin of students' stress}

It is obvious that students meet different situations that provide stress, such as relationships with new students; personal factors that vary from person to person; e.g. movement from a small hometown or village to a big city; changes in sleeping habits. This means when students have large academic workloads, they often suffer from lack of sleep. They also have new responsibilities and sometimes combine a job with the studies. Also they may have financial difficulties, if they should pay for their education. There may be health problems and poor eating habits when because of studies, students do not have enough time to do physical activities and to cook for themselves etc.

In terms of academic factors there are various challenges to outline, for instance, increased academic workload, especially when there are a large amount of assignments; lower tham expected grade, which means, when students receive a lower than expected grade and are seriously disappointed. Excessive amount of hours of study which means students spend most their time studying and they do not have time to relax with their friends; language difficulties, see the picture below [11] while educational language is for some students like their native tongue for other students it is as foreign as a second language. Procrastination which means students put off their assignments until the last possible moment and then end up with no time to do the work properly. Examinations: these are the only means for a student to prove that they deserve a better grade for a course and because of this students tend to overthink and even obsess about the course work and also try to revise everything they have learnt during the whole period of the course. In doing so, some students get overwhelmed and confused about many topics, and they do not know what to do next with their studies. Missing lectures: it is a common desire of students to miss lectures and when this happens they start to wonder how they will make up for the lessons they have missed so they will be on the same level as their fellow students.

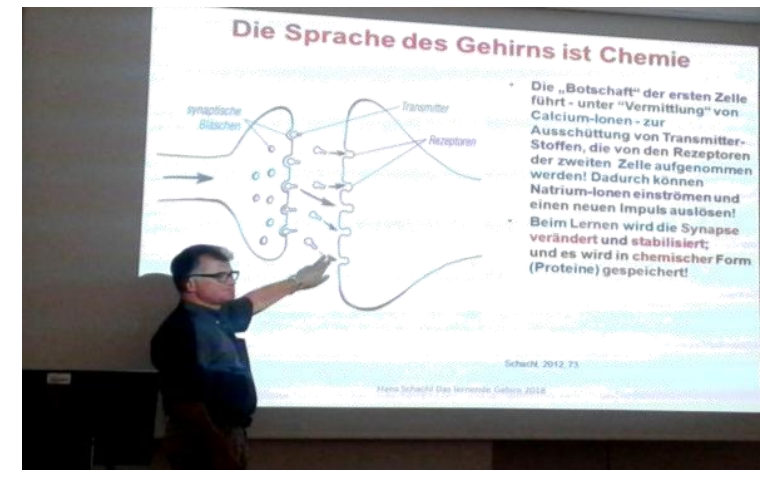

Private photo, Prof. Dr. Hans Schachl is holding lecture at the Pedagogical University in Upper Austria

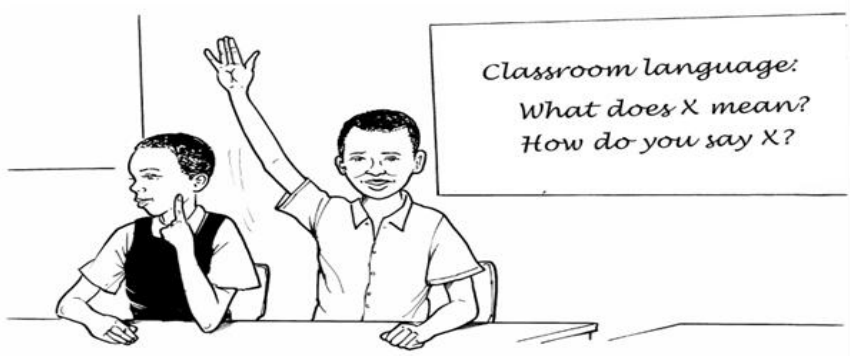

Please, teacher, what does X mean?

Poor living conditions can play a major role in the moods and general well-being of students. When students live in conditions which are sub-standard and it is difficult for them to afford some basic amenities, they can easily become depressed and obviously this affects all aspects of their lives, especially their studies.

\section{Mental health problems}

As is well known, stressful events can be very common in both private and professional life, and above all, in universities! Studies suggest that many students and lecturers experience significant mental health issues. Stress is a major problem in higher education! Stress-related disorders can impair cognitive functions and thereby lead to poor achievements with exams [12, 13]. Mental health difficulties contribute to problems with achievement and relationships at colleges [14]. In severe cases, they prevent students from regularly attending class, but more often students simply struggle with these problems on a daily basis, leading to further negative social and academic function [15]. The word stress conjures up thoughts of depression, negativity and anxiety and other potentially life-threatening issues even including suicide. With this in mind, we conducted a survey on how stress effects students. This included questions as to how this word is perceived by students: Questions below were asked randomly in three different Kazakh universities: The Abai Kazakh Pedagogical University and The Institute of Metallurgy and Ore Benefication and The Almaty Management University. All students were required to complete the survey, which contained demographic information and four questionnaires. The demographic information was used to ascertain each student's information, such as gender and place of study. Our research was intended 
to address the following questions and almost all the answers were approximately similar.

\section{Questions given to the students:}

\section{How do you understand the word stress?}

Typical answers given by students: A state of mental or emotional strain or tension resulting from adverse or demanding circumstances;

The state of a person in which they experience negative emotions, also it affects the physical energy of a person causing fatigue;

Stress is your body's way of responding to any kind of demand; when your morale is very low;

Stress is primarily a physical response activated by negative mental attitudes.

When stressed, the body thinks it is under attack and switches to 'fight or flight' mode, releasing a complex mix of hormones and chemicals such as adrenaline, cortisol and norepinephrine to prepare the body for physical action;

Stress indicates your nervous system is unbalanced, which can affect a person on many levels;

A person feels psychological pressure which can result from problems at work, personal problems, studies etc.

For students this often happens when it comes to assignments, exams, deadlines etc. If it goes unacknowledged, it could turn into serious health issues and result in low academic performance...

In your opinion, does stress influence students' academic life?

Without exception all students answered identically: yes

In your point of view should stress awareness be taught in the educational organisations such as schools and universities?

Without exception all students answered identically: yes

\section{How do you feel when you are stressed?}

Answers given by students: "I feel under extreme pressure, and at some points I feel, I cannot control my fate. Therefore, one needs to step aside and relax and in order to clear their thoughts afterwards continue with their endeavors."

"I feel so unhappy, constantly depressed."

"My mood goes down, I become aggressive."

"I feel isolated. I cannot eat and sleep. Also I do not have any desire to communicate with people. I think about the problem all the time. Sometimes I want to listen to music especially motivational music, in order to raise my mood."

The goal of this survey was to identify how stress is perceived, and to ascertain, whether it is neccessary to give seminars on stress management. It clearly showed the neccesity for workshops, seminars, and even compolsury courses in order to help students cope with stress and to avoid mental health problems and other negative results. We therefore recommend future studies to use a more elaborate questionnaire to investigate the effects of stress on academic performance and mental health in more depth.

\section{Young people with mental health issues usually do not receive help!}

Most young people do not receive treatment for mental health difficulties $[16,17,18]$. Due to the high prevalence of stress, it is important to consider alternative ways and methods during the educational proccess for promoting the socialemotional well-being of Kazakhstani young people. Educational establishments should be pro-active in promoting positive mental health, identifying and intervening as early as possible to prevent the onset of serious problems, and respond to both children and young adults in distress [15]. Regarding the negative impact of stress at intrapersonal and somatic levels, it is important for healthcare professionals to master a repertoire of stress management techniques and teach them to their patients. This also could be done when students embark on the high education. It should be noted that stress management techniques are applicable not only to people who manifest a disease or mental disorder, but also to healthy people. For it has been proven that when added to ones daily routine practice it is an effective tool for health enhancement and protection over the whole of the life span. Health promotion, as one of the main approaches to health enhancement, can serve this multiple role by designing and applying interventions to reduce or prevent distress and adequately contribute to future health and wellness throughout the whole of society [19]

\section{Problem solving methods}

There are two central vehicles that can be adopted for broad knowledge sharing in relation to coping with stress during the educational proccesses: dedicated online courses and face-to-face communication. There are other options as well, for example, with the help of the Mental Health Commission of Canada [15], an interactive site has been created. This consists of yoga courses and music among other things to relieve stress. Online lessons for parents and students through the internet. A searchable database of all of the nominated programs from the internet has been created to assist school boards in learning about existing activities from across the country and beyond.

\section{RESULTS AND DISCUSSION}

\section{Stress management techniques}

The ability to manage stress is really an important issue when it comes to the topic of stress. Due to this, the Canadian Clinic Community Health Centre has laid down some stress relieving techniques which can help a lot, especially for students [3]

Below there are some techniques and methods that can help reduce stress.

Relaxation means to treat and relax all stress centres in the body and gradually check mechanisms, that may lead to stress, thereby reaching complete relaxation both inside and outside the body. 
In this process, all the muscles, internal organs and joints of the body, as well as the emotions and the mind should become relaxed. In the beginning, relaxation should be a conscious effort, though in the end all parts of the body including the mind, should be naturally relaxed.

Stress is a factor that may cause disease of the body and the mind. When stress appears in any part of the body, the natural function of that part oft he body may be impaired, and a state of disorder may gradually develop. When this disorderly state reaches a certain level, disease will be the result. Therefore removing stress can mean eradicating the source of some illnesses [20].

A technique that can help with the management of stress is meditation. It cultivates mindfulness and it can be particularly effective at reducing stress, anxiety, depression, and other negative emotions. Mindfulness is the quality of being fully engaged in the present moment, without overthinking or analysing the experience. Rather than worrying about the future or dwelling on the past, mindfulness meditation switches the focus on what is happening right now. Mindfulness meditation is not equal to zoning out. It takes an effort to maintain your concentration and to bring it back to the present moment when your mind wanders or you start to drift off. However, with regular practice, mindfulness strengthens the areas of the brain associated with joy and relaxation. Mindfulness provides a potentially powerful antidote to the common causes of daily stress such as time pressure, distraction, agitation, and interpersonal conflicts [3].

Another method, which is easy to practice, is deep breathing: It releases tension from the body and clears the mind, improving both physical and mental wellness. We tend to breathe shallowly or even hold our breath when we are feeling anxious. Sometimes we are not even aware of it. Shallow breathing limits your oxygen intake and adds further stress to your body. Breathing exercises can help to reduce this stress. The key to deep breathing is to breathe deeply from the abdomen, getting as much air as possible into your lungs. When you take deep breaths from the abdomen, rather than shallow breaths from your upper chest, you inhale more oxygen. The more oxygen you get, the less tense, short of breath, and anxious you feel. This kind of breathing is called "diaphragmatic breathing". It means to breathe from the depths of your abdomen, rather than from your chest [3].

\section{Diaphragmatic Breathing:}

Origin: the natural act of breathing has been used as a means of relaxation intuitively in many cultures over many millenia. It has been an integral part of different yoga traditions and is now incorporated in many modern relaxation programs.

Method/Patho-physiology: diaphragmatic breathing, or abdominal or belly or deep breathing is marked by expansion of the abdomen rather than the chest when breathing. Diaphragmatic breathing is defined as a manipulation of breath movement, contributing to a physiologic response characterized by (a) the presence of decreased oxygen consumption, decreased heart rate and blood pressure, and (b) increased theta wave amplitude in EEG recordings, increased parasympathetic activity accompanied by the experience of alertness and invigorating [19].

It is hypothesized that voluntary slow deep breathing functionally resets the autonomic nervous system through stretch-induced inhibitory signals and hyperpolarisation currents propagated through both neural and non-neural tissue which synchronizes neural elements in the heart, lungs, limbic system and cortex [19]. Patients are taught by a trained professional, manual or audio how to inhale and exhale deeper and slower. They need to practice several times a day, or as needed, for a few minutes to see immediate benefits.

Results/Benefits: Deep breathing has been successfully used to decrease the fatigue associated with haemopoietic stem cell transplantation patients [19], to reduce the anxiety and asthma signs/symptoms of children with asthma [19], in the management of acute stressful tasks [19] showing that the slow-breathing technique can have a significant effect on improvement of the hemodynamic changes following the acute stressful tasks.

The Power Breath (See picture): stand straight with your arms by your sides. Inhale deeply and completely, filling yourself with the breath to maximum capacity. Hold the breath for half a minute.

Then exhale powerfully through the mouth with your lips like a pipe. As you exhale through the mouth, draw your lower abdomen in tightly, squeezing the breath out. When you have completed the exhalation, inhale tightly, exhale, and relax for a moment. This breath can be performed up to seven times.

The power breath supercharges the bodymind. It saturates your entire system with prana (Prana is the Indian word for the energy of the breath). It develops mental clarity, purifies the blood, and builds strong, powerful lungs [21].

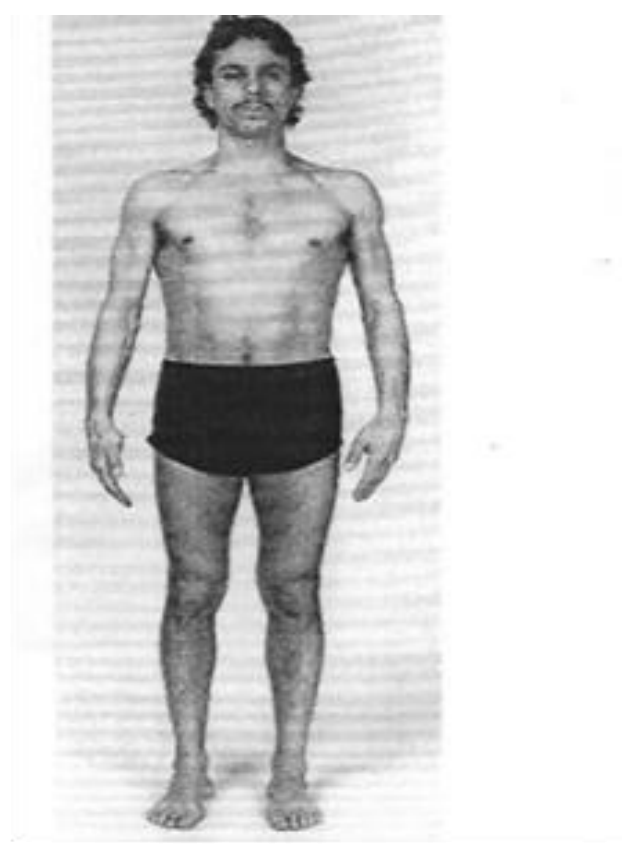

Whether something or someone creates stress or not, depends on the personal evaluation of the situation. The individual "appraisal" of possible stressful events and stressors 
and also the available methods of coping with them determine, whether the biological reactions occur and impair the subject or not. Because of "subjectivity" (genetics, prior experiences) we have different reactions to stress and we need different coping-strategies. In addition to the "physiological methods" (see above) we need also "mental techniques":

"Instrumental" management of stress:

We need competencies in the subjects we have to learn; that means, we must learn to learn. We need further social competencies (mutual supporting etc.); self-management competencies (planning, organising, preparation for exams in time, establishing a good working place, ...). Very important, but the most difficult one is mental management of stress: accepting the reality, self-control (accepting the own limits, for instance to ask, whether the steps are too high), critical analysis of one's own appraisals (am I really a loser?), comparison of all achievements), change of thinking (exams as challenges, not as threats), self-affirmations' (I will succeed, I am well prepared, etc ...).

\section{Important note for teachers:}

Teaching should be more focused on strengths rather than on weaknesses. Negative criticism can have devestating effect on young, vulnerable minds.

Further special techniques for "regenerative" management of stress is beside yoga, meditation and breathing (see above) are autogen training, and Jacobson's progressive muscle relaxation.

The Jacobson technique of progressive muscle relaxation (see picture picture in google engine) is very easy and works well to come down from high-level stress. Combined with yogic breathing it is very effective. "Breath concetration meditation" has positive impacts on regulating adverse emotions, by lowering the activation of the amygdala [13].
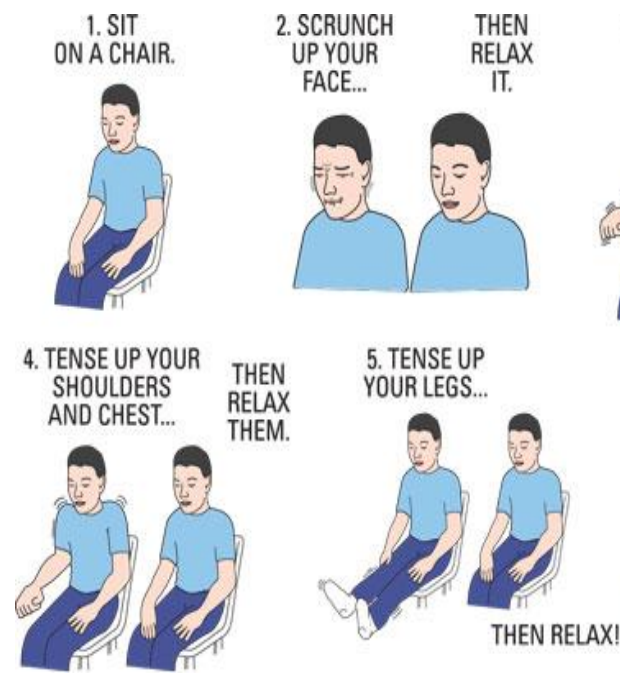

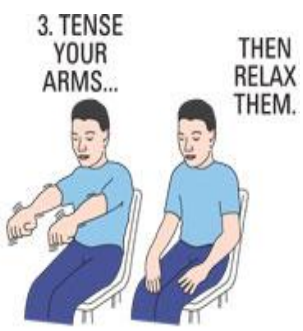

6. BREATHE IN RELAXATION.

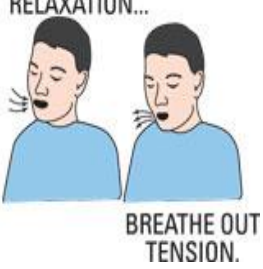

Progressive Muscle Relaxation Training (Picture from google engine)

\section{Progressive Muscle Relaxation (PMR):}

Origin: PMR is a technique for reducing stress and anxiety by alternately tensing and relaxing the muscles [19]. It was developed by American physician Edmund Jacobson in the early 1920s. Jacobson argued that since muscle tension accompanies anxiety, one can reduce anxiety by learning how to relax the muscular tension. PMR entails a physical and mental component [19]. You can also surf "Progressive Muscle Relaxation Training" created by headache specialists at Children's Mercy Hospital together with Bazillion Pictures, Inc in www.youtube.com.

Method/Patho-physiology: The physical component involves the tensing and relaxing of muscle groups over the legs, abdomen, chest, arms and face. In a sequential pattern, with eyes closed, the individual places tension in a given muscle group purposefully for approximately 10 seconds and then releases it for 20 seconds before continuing with the next muscle group. The mental component requires that the individual focuses on the distinction between the feelings of the tension and relaxation. With practice, the patient learns how to effectively relax in a short period of time [19].

Results/Benefits: Among PMR's long-term benefits the following are included: reduction of salivary cortisol levels and generalized anxiety, decreased blood pressure and heart rate, decreased headache, better management of cardiac rehabilitation, improvement of quality of life of patients after bypass surgery and improvement of quality of life of patients with multiple sclerosis [19].

Result of this study: The outcome provides the basis for enhancing the general adoptation of a new, positive approach to a student's life, thereby ensuring academic success.

Discusion: It would be useful for future studies to consider the extent to which stress management techniques have contributed to the academic performance of students. Given that children and young people spend a substantial part of each day within the educational setting, these communities become a natural and important venue for mental health service delivery [22]. It is obvious, that many parents are busy with everyday life and household chores and do not have enough time to spend with their children. Unfortunately, it is obvious, that more and more young people are spending their free time on surfing the internet, which impacts their mental health. While it is a helpful tool for education, work, social interaction and entertainment, overuse can take a toll on your health, says Saju Mathew, [23] a primary care physician at Piedmont healthcare. Excessive smartphone, computer and tablet use can disrupt your sleep, which affects your emotions as well as your physical well-being. Stress may cause you to have trouble staying asleep, not necessarily falling asleep. "It's more common to be waking up at 3 or 4 a. m., not knowing what woke you up," says Walter James, [24] a sleep medicine physician at Piedmont Atlanta Hospital. "There could be intrusive thoughts about stress." Also, busy schedules crammed with studies and extracurricular activities can take a toll on students' physical and mental health, especially if they are not eating or sleeping properly. If untreated, these stressors can compound over time, leading to even greater levels of 
stress, say George Essel and Patrick Owusu in their case study project work completed at the Seinäjoki University of Applied Sciences in 2017 [3]

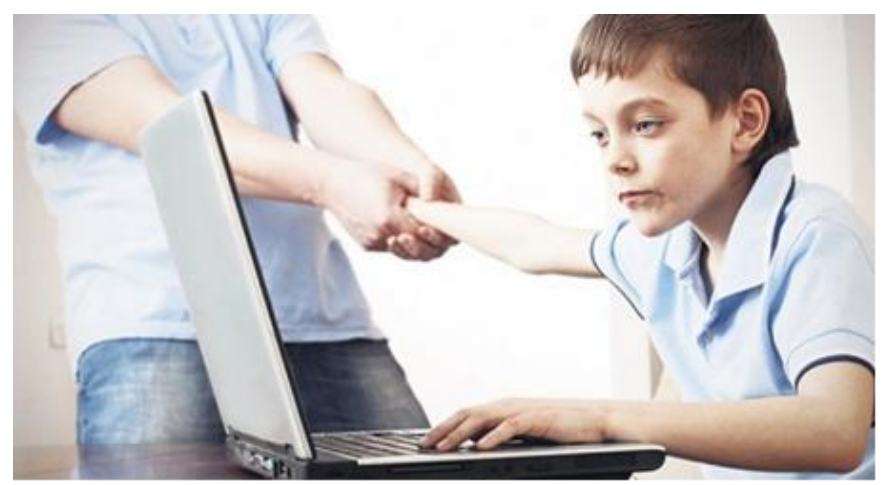

How the Internet affects your mental health (Google engine - Internet Addiction)

In fact, "development of the school as a site for the effective delivery of mental health services is essential" [25]. There are several unique advantages to offering mental health programming within the school setting. For example, classwide programs may reach students, who would not access formal children's mental health services [26]. Further, since attendance and classroom expectations support course and homework completion, students are more likely than clinicreferred children to receive an intervention they require and less likely to discontinue treatment [27, 28]. Also, during class-wide social emotional learning instruction, higher risk students may benefit from observing emotionally-skilled peers model of good coping behaviour and attitudes [29]. While school-based programming facilitates the early identification of difficulties when they first emerge [30], it also has the potential to maximize positive mental health development for all children, not only for those who are on a negative trajectory [31]. Finally, the implementation of empiricallysupported mental health promotion and prevention programming in schools is associated with improved emotional and behaviour functioning [32, 33], enhanced academic performance [33]. Trying to get a grip on such issues is a challenge that should be taken on in future research. Future studies could help to clarify, whether this actually is a valid explanation.

\section{Mental Health Promotion}

An essential advantage of school programming is the opportunity to promote positive mental health of all students rather than focusing solely on those identified as having mental health problems. Community, school, and classroom efforts all create a culture of well-being and a sense of belonging for all students [34]. B. D. Zhigitbekova [35], a candidate of phsychological science and senior teacher at Abai Kazakh National University in Kazakhstan, says it is noteworthy that role-playing games contribute to socialization and adaptation to life situations. Adventure-role plays help prevent stress-related problems. By absorbing the exceptional experience of overcoming all adverse effects, it is not just a restart, but also a gambling experience and this is an opportunity to overcome adverse events in real life situations. Another study at the University of Miami by Hollar [36] showed that short interruptions (10-15 min) of lessons, filled with some physical exercises, led to better performances in mathematics and language courses. A long-term study at the Universities Glasgow and Dundee on 5000 pupils [36] showed that regular physical exercise from the age of 11 until 16 improved marks in English, mathematics and sciences. The California Department of Education found that higher cognitive processes (steered by hippocampus and prefrontal cortex) were improved by physical fitness [37]. Running, riding bicycles, swimming etc. increased creativity (shown by a study of Stanford University) [38].

Encouraging results made by the mental health commission of Canada for mental health promotion activities such as skills training, role playing, positive feedback, modeling and self-reflection give the following warranty:

$>$ Social skills training or social emotional learning can be effective in bolstering students' coping ability, and in addressing an array of emotional and behavioural problems. In addition, social emotional learning has been associated with enhanced academic achievement [33].

$>$ In general, programs are more effective, when skills are taught systematically, in a class-wide manner, involve the whole school, and are implemented over more than one year.

- Universal programs can be effective in improving the well-being of children and young adults.

Strategies such as school-based peer identification and response training (how to recognize risk and promote helpseeking), family support, appropriate skills development and professional training for mental health of staff and educators appear to be helpful. Early identification and treatment of mental health problems are key components of suicide prevention [15].

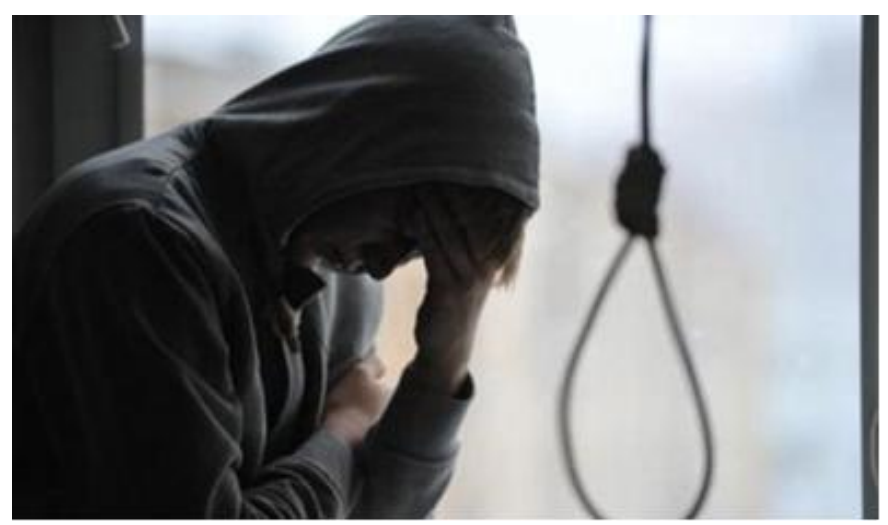

The number of young people who committed suicide in Kazakhstan recently. [39]

\section{Adverse effects of stress on students}

Students today experience high levels of stress in many areas of life. This is an important domain for further research and an effective channel of intervention for university mental health professionals. Study schedules, especially in universities, are very challenging. The act of combining a busy life along with education causes stress and depression. Limited 
stress is beneficial and can lead to excellent performance. However, uncontrolled stress can lead to exhaustion, depression and several other sicknesses. In fact, college students are prone to episodic stress. This happens when exams are around the corner. Stress and depression also occur when getting ready for a presentation or an interview. At these times some students contemplate or even commit suicide [3]. In Kazakhstan today suicide of young people is a serious problem. There is a higher chance of a young person dying by their own hand than there is of them being murdered. Tragically, on average, more than two thousand people commit suicide a year according to informburo.kz. Kazakhstan is among the top ten countries in the world regarding suicides. In 2012 , the country took the ninth place in suicides by young people including many children. In the period from 2007 to 2012, the figures fell somewhat, but in 2015, there was an increase of $20 \%$. According to the Minister of Religious Affairs and Civil Society, Nurlan Yermekbayev, nine out of ten teenagers who commit suicide, do it, not to kill themselves, but to have their problems heard. It is a cry for help, but tragically, at this point the help can never be given. [40].

Our educators must be the ones to prevent this catastrophic and distressing situation. Professionals who work in educational organizations must be made aware oft he terrible possibilities and be made to look for warning signs in their students. Most mental health problems can be detected prior to the age of 24 , and $50 \%$ of these difficulties surface before the age of 14 [41].

\section{Recommendations for action}

This article also features recommendations about positive mental health knowledge-sharing practices and activities. Hopefully, more educational organizations from kindergarden to high schools and especially to universities, will actively promote the social-emotional well-being of Kazakhstan's young people. There is sufficient research into the area of mental health in educational establishments from Kindergarten to University, to implement policy and practice of boosting and monitoring the mental health of the young generation of Kazakhstan.

The culminative results of research work point to an urgent need for:

1. Attention to organizational conditions for effective school mental health at the provincial, district and school/community level. Organizational conditions include proper educational plan, protocols for decisionmaking, systematic training, role clarity, implementation, collaboration, and system communication. Ensuring adequate numbers of trained mental health professionals in schools is also part of this required commitment, if we are to be successful across the continuum of care.

2. Systematic professional learning in mental health for all educators and students.

3. Rigorous evaluation of untested but research-informed approaches. More foundational research is clearly needed in certain areas; most critically, substance abuse prevention and intervention in schools, suicide prevention and educator mental health literacy and mental health for schools with special populations.

4. Because schools are an excellent place to promote positive mental health, more needs to be done to take advantage of the growing number of school/community partnerships, coalitions and net-works focused on moving the field forward. Inclusive partnerships also must include the meaningful participation of young people and their families.

5. Investment in evidence-informed mental health promotion within a school context. This includes a method for organizing the current patchwork of mental health programs in class programming $[42,15]$.

6. Having positive relationships with those around you during the educational process, is of paramount importance as it helps to reduce the level of stress in the classroom. Obviously good communication plays a key role in the educational environment and good educators must make it their business to be aware of the mental states of their students.

\section{CONCLUSION}

In summary, it is worthy noting that stress is an inevitable part of student life. However, research has found clear evidence for the effectiveness of activities during lessons for positive mental health promotion, prevention and treatment of internalizing and externalizing disorders. An important element for success is the match between the program and the needs and resources of the setting. There is an insufficient body of evidence to provide direction for special populations; such as specific cultures, clinical needs, or a targeted age group. Also, to be effective, the personnel needs training and support to ensure that strategies are delivered with fidelity to the original program's methodology. Finally, programs require monitoring of process and outcomes to make sure they are achieving the desired results or require modification for the local context. Successful implementation requires dedicated leadership, proper preparation of the organization, and ongoing support for implementation, treatment integrity, and evaluation of program outcomes.

Current scientific ideas support the notion that stress management techniques can lower stress levels of the organism, resulting in reduction of disease symptoms, lowering of biological indicators of disease, and prevention in life. As stress is universal and of relevance to all, a more thorough understanding of stress management techniques is essential for preventing stress related diseases and enhancing health overall. It is concluded, that progressive muscle relaxation and diaphragmatic breathing are all effective treatment methods for reducing stress and anxiety that accompanies daily life and chronic illness. The stress reduction techniques reviewed in this paper also improve the quality of life of students and in many cases contribute to the reduction of disease symptoms. The same techniques are also therapeutic for teachers enhancing their interactions with students. No negative side effects from any of those techniques have been documented. However, the literature shows, that there is a need for more extensive control trials of the aforementioned stress-reduction techniques in order to 
establish their usefulness in the prevention and stress management during studies.

\section{ACKNOWLEDGMENT}

We would like to thank the Institute of Pedagogy and Psychology at Abai Kazakh National Pedagogical University and the Institute of Metallurgy and Ore Beneficiation at Satbayev University, the English Language Department at Almaty Management University for their allowance to carry out our survey. We express great gratitude to all students who answered our questionnaires. The work is financially supported by Ministry of Science and Education of the Republic of Kazakhstan.

\section{REFERENCES}

[1] H. W. Krohne, Stress and Coping theories, available online https://ru.scribd.com/document/56298659/Krohne-Stress-26-Mei-2011 , 2002, pp.1-2.

[2] C. M. Wheeler, Ten simple solutions to stress, how to maintain tension. Start enjoying our life. USA: New harbinger publications Inc., 2007, p.2.

[3] G. Essel and P. Owusu, Causes of students' stress, its effects on their academic success, and stress management by students, Case study at Seinäjoki University of Applied Sciences, Finland, Thesis, https://www.theseus.fi/bitstream/handle/10024/124792/Thesis\%20Docu ment.pdf?sequence=1 , 2017, pp.15-34.

[4] L. Dusselier, B. Dunn, W. Yongyi, II M. Shelley \& D. Whalen, Personal, health, academic, and environmental predictors of stress in residence halls. Journal of American College Health, 54(1), 2005, pp.15-24.

[5] E. Hoover, More help for troubled students, December 5, 2003.

[6] Centre for studies on human stress, Biology of stress, http://humanstress.ca/stress/what-is-stress/biology-of-stress/.

[7] Z. A. Cordner, K. L. K. Tamashiro, Effects of chronic variable stress on cognition and Bace1 expression among wild-type mice. In: Translational Psychiatry, 6, doi: 10.1038/tp.2016.127, 12. July 2016.

[8] B. S. Ewen, Stress-induced remodeling of hippocampal CA3 pyramidal neurons. In: Brain Research, 1645, 2016 pp.50-54.

[9] https://en.wikipedia.org/wiki/Telomere

[10] H. Schachl, Das lernende Gehirn, manuscript unpublished. 2017 p.45.

[11] W. Dave, Rules, Pattern and Words, Cambridge University Press, 4th printing, 2009, p.5.

[12] S. Vogel, L. Schwabe, Learning and memory under stress: implications for the classroom. In: npj Science of Learning 1, doi: 10.1038/npjscilearn.2016.11, June 2016.

[13] H. Schachl, Neuroscience: A Traditional and Innovative Approach to Education with Focus on Stress with Learning. In: SIGNUM TEMPORIS. Band 8, Heft 1, ISSN (Online) 1691-4929, DOI: https://doi.org/10.1515/sigtem-2016-0012, 2016, pp.9-21.

[14] E. Chang, Z. Zadeh, N. Jhang \& M. Mak, Depression and academic achievement: A metaanalysis. Poster presented at the Canadian Acamemy of Child and Adolescent Psychiatry, Vancouver, BC., September 2008.

[15] Mental health commission of Canada. School- based mental health in Canada: A final report, https://www.mentalhealthcommission.ca/sites/default/files/ChildYouth School_Based_Mental_Health_Canada_Final_Report_ENG_0.pdf , September, 2013.

[16] D. R. Offord, M. H. Boyle, P. Szatmari, N. I. Rae-Grant, P. S. Links, D. T. Cadman, J. A. Byles, J. W. Crawford, Munroe Blum H., Byrne C., H. Thomas \& C. A. Woodward, Ontario Child Health Study II: Six-month prevalence of disorder and rates of service utilization. Archives of General Psychiatry, 44, 1987, pp.832- 836
[17] P. Rohde, P. M. Lewinsohn \& J. R. Seeley, Co-morbidity of unipolar depression: II. Comorbidity with other mental disorders in adolescents and adults. Journal of Abnormal Psychology, 100, 1991, p.214-222.

[18] C. Waddell, C. Shepherd, A. Chen \& M. Boyle, Creating comprehensive children's mental health indicators for British Columbia. Canadian Journal of Community Mental Health. 32 (1), 2013, p.9-27.

[19] L. Varvogli and C. Darviri, Stress Management Techniques: evidencebased procedures that reduce stress and promote health, Health science journal, volume 5, issue 2, 2011, p.74-89.

[20] Yu Gongbao, Wushu Exercise for Life Enhancement, Foreign Language Press - Beijing, 1991, p.10.

[21] Christopher S. Kilham, Inner Power, Japan Publications, Inc., 1988, p.45.

[22] National Research Council and Institute of Medicine. Preventing Mental, Emotional, and Behavioral Disorders Among Young People: Progress and Possibilities. Committee on Prevention of Mental Disorders and Substance Abuse Among Children, Youth and Young Adults: Research Advances and Promising Interventions. Mary Ellen O'Connell, Thomas Boat, and Kenneth E. Warner, Editors. Board on Children, Youth, and Families, Division of Behavioral and Social Sciences and Education. Washington, DC: The National Academies Press, 2009.

[23] Piedmont healthcare: 7 ways to get a better night's sleep, https://www.piedmont.org/living-better/7-ways-to-get-a-better-nightssleep

[24] Piedmont healthcare: How the Internet affects your mental health, https://www.piedmont.org/living-better/how-the-internet-affects-yourmental-health .

[25] M. J. L. Kirby \& W. J. Keon, Out of the shadows at last: Transforming mental health, mental illness and addiction services in Canada. Standing Committee on Social Affairs, Science and Technology, 2006, p.138.

[26] T. R. Kratochwill \& E.S. Shernoff, Evidence-based practice: Promoting evidence-based interventions in school psychology. School Psychology Quarterly, 18(4), 2004, pp.389-408.

[27] A. E. Kazdin, L. Holland \& M. Crowley, Family experience of barriers to treatment and premature termination from child therapy. Journal of Consulting and Clinical Psychology, 65, 1997, pp.453-463.

[28] A. E. Kazdin, J. L. Mazurick \& D. Bass, Risk for attrition in treatment of antisocial children and fami-lies. Journal of Clinical Child Psychology, 22, 1993, pp.2-16.

[29] H. M. Lowry-Webster, P. M. Barrett \& M. R. Dadds, A universal prevention trial of anxiety and depres-sive symptomatology in childhood: Preliminary data from an Australian study. Behavior Change, 18, 2001, pp. 36-50.

[30] J. S. Middlebrooks \& N. C. Audage, The effects of childhood stress on health across the lifespan. Atlanta, GA: Centers for Disease Control and Prevention, National Center for Injury Prevention and Control, 2008.

[31] L. Rowling \& M. D. Weist, Promoting the growth, improvement and sustainability of school mental health programs worldwide. International Journal of Mental Health Promotion, 6 (2), 2004, pp.3-11.

[32] M. Greenberg, |C. Domitrovich \& B. Bumbarger, The prevention of mental disorders in schoolaged children current state of the field. Prevention and Treatment, 4(1) Available online at: http://journals.apa.org/prevention/volume4/pre0040001a.html , 2001.

[33] J. A. Durlak, R. P. Weissberg, A. B. Dymnicki, R. D. Taylor \& K. B. Schellinger, The impact of enhancing students' social and emotional learning: A metaanalysis of school-based universal interventions. Child Development, 82 (1), 2011, pp.405-432.

[34] L. Rowling, Australian perspectives on findings from the national SBMHSA Scan, Survey and Review. Paper presented at the 3rd National Symposium for Child and Youth Mental Health, Calgary, AB., 2012.

[35] B. D. Zhigitbekova, The role and place of psycho-physics in group psychological training [Toptıq psïxologïyalı trenïngtegi psïxogïmnastïkanıñ ornı jäne röli] // Bulletin of Abai KazNPU, Series «Psychology» №4 (53) 2017, pp.61-66.

[36] F. Beck, Sport macht schlau: Mit Hirnforschung zu geistiger und sportlicher Höchstleistung. Wien: Goldegg Verlag, 2014, p.18. 
[37] T. Landrichinger, Die Implementierung der „Bewegten Schule“ als Instrument und systemischer Ansatz der kontinuierlichen Schul- und Unterrichtsentwicklung in der Sekundarstufe 1 in Oberösterreich Bedeutung der Schulleitungen und der Schulaufsicht in Bezug auf Rahmenbedingungen, Vorgehensweise, Strukturen und Entscheidungsprozesse. Master Thesis an der Donau Universität Krems, 2015 .

[38] W. Suzuki, B. Fitzpatrick, Fittes Gehirn, erfülltes Leben. München: Goldmann. English Version (2015): Healthy Brain, Happy Life. Verlag Dey Street, 2016.

[39] Zakon.kz, https://www.zakon.kz/4855473-skolko-chelovek-vkazahstane-pokonchili.html , April 2017.

[40] Inform БЮРО, The sad statistics of suicides in the world and Kazakhstan were shown in infographics [Pechal'nuyu statistiku samoubiystv v mire i Kazakhstane pokazali v infografike], https://informburo.kz/novosti/pechalnuyu-statistiku-samoubiystv-vmire-i-kazahstane-pokazali-v-infografike.html , January 2017.

[41] R. C. Kessler, P. Berglund, O. Demler, R. Jin \& E. E. Walters, Lifetime prevalence and age of onset distributions of DSM-IV disorders in the National Comorbidity Survey Replication. Archives of General Psychiatry, 62, 2005, pp.593-602.

[42] G. K. Kassymova, H. Schachl, O. S. Sangilbayev, Enhancing students' concentration on lesson in stress situation, The First Internationa Scientific and Practical Internet Conference «Science and Education in the 21st Century,» Public Fond « Bridges of Consent « Astana, Kazakhstan, February 2018, pp.7-11.

[43] S. Vogel, L. Schwabe, Learning and memory under stress: implications for the classroom. In: npj Science of Learning 1, doi: 10.1038/npjscilearn.2016.11, 29 June 2016.

[44] G. Roth, N. Strüber, Wie das Gehirn die Seele macht. Stuttgart: KlettCotta, 2015, p. 135 